\title{
Falsificationism and the Pragmatic Problem of Induction
}

\author{
Danny Frederick*
}

Received: 1 October 2019 / Accepted: 4 August 2020

\begin{abstract}
I explain how Karl Popper resolved the problem of induction but not the pragmatic problem of induction. I show that Popper's proposed solution to the pragmatic problem of induction is inconsistent with his solution to the problem of induction. I explain how Popper's falsificationist epistemology can solve the pragmatic problem of induction in the same negative way that it solves the problem of induction.
\end{abstract}

Keywords: Conjecture; falsification; induction; Karl Popper; pragmatic problem of induction; rational action.

\section{Introduction}

The problem of induction seems to threaten the possibility of empirical knowledge. The standard response is to try to show that the problem is not real by arguing, in some specious way or other, that we have justified claims to knowledge. Karl Popper's response is to bypass the problem by showing that we can have knowledge without justification. However, unjustified theories do not seem to supply a basis for rational action. That is the pragmatic problem of induction. Popper's solution to that problem has satisfied few.

* unaffiliated

13 Sandhurst Road, Yeovil, Somerset, BA20 2LG, United Kingdom

$\triangle$ dannyfrederick77@gmail.com

(C) The Author. Journal compilation (C) The Editorial Board, Organon F.

This article is distributed under the terms of the Creative Commons Attribution-NonCommercial 4.0 International Public License (CC BY-NC 4.0). 
I show that Popper's solution to the pragmatic problem of induction is inconsistent with his solution to the problem of induction. I advocate resolving the pragmatic problem of induction in line with Popper's epistemology.

\section{Induction}

The problem of induction was formulated by David Hume. An individual observation provides us with information about itself but it provides us with no information about other observations that we may make. Consequently, our general theories about the world cannot be derived from, or justified by, our observations. For example, even if every swan that we have observed has been white, it does not follow that swans that we have not observed will also be white; and it does not follow that it is probable that swans that we have not observed will be white, because we can have no idea whether our experience of things so far has been representative of how things are in general. We can therefore have no justification for thinking that our general theories are either true or even probably true. We may find our general theories plausible, or 'subjectively probable,' given our particular experiences or inclinations; but we can have no grounds for linking such plausibility or subjective probability to truth or to objective probability (Hume 1888, part III, section vi, 86-94 and section xii, 139; part IV, section ii, 218; 1975, section IV, part II, 32-39; section V, part I, 40-47).

In general, philosophers who have responded to Hume's problem have tried to show that Hume was mistaken. Some philosophers, including Kant, have attempted to show that some of our general theories can be justified a priori. Such attempts were discredited more than a century ago. Gottlob Frege's fifth axiom for arithmetic, which had been assumed to be self-evident, was shown by Bertrand Russell to be self-contradictory. As a consequence, for all we can know, any proposed a priori justification might fail because it contains a latent inconsistency (Russell 1959, 58). The point was underscored in 1931 by Gödel's second incompleteness theorem, which showed that any theory that assumes arithmetic, as virtually all theories of any interest do, cannot be proved to be consistent. Other philosophers have tried to show that our general theories are justified in a weak sense, that they are "supported" or "prima-facie justified." However, these philosophers 
admit that such weakly justified theories may turn out to be false. They therefore provide no solution to Hume's problem. It remains the case that we are not justified in thinking that our general theories are true or even probably true in an objective sense of 'probability.' Indeed, even if it could be shown that supported or prima-facie justified theories were, objectively, probably true, we would not be justified in thinking them to be true, since even a highly probable theory may still be false.

Karl Popper (1972a) showed the way out of this quagmire. The fact that we cannot obtain general theories that are justified is not a calamity because we can proceed well enough with general theories that are conjectures that we test against statements describing particular events that we observe. All such observation statements are theory-laden; but we can usually reach agreement on such observation statements because we can usually find a way of describing our observations that is neutral between whatever theories are currently in contention (Frederick 2016, 641). If a general theory contradicts such an observation statement, we reject it, otherwise we retain it for additional testing. Further, since any of our conjectures may be false and may, indeed, end up being rejected after testing, we should strive to come up with better conjectures than the ones we already have, either by modifying existing conjectures or by propounding novel ones, and we should look for ways to test those conjectures. We can agree that one unrefuted conjecture is better than another if it explains more or explains more simply and if it implies more novel empirical predictions that survive testing. What we should not do is waste time trying to justify any existing conjectures, not only because it cannot be done, but also because it is an attempt to block progress, to stand still instead of moving forward. Contemporary epistemology, being preoccupied with justification, is thus epistemically perverse: it stands opposed to the growth of knowledge.

Philosophical objections to Popper's response to Hume's problem tend to focus on issues concerning falsification and truth. It is frequently objected that scientific theories are usually so general that they clash with no observation statements: it is only a conjunction of such theories plus statements describing particular situations that are inconsistent with observation statements. However, all that means is that, when such an inconsistency appears, we have a choice of which theory or statement to revise. Popper proposes 
that any revision is acceptable if, but only if, it solves a problem in addition to the problem of removing the inconsistency; and, ideally, it should imply novel falsifiable predictions that survive testing. Thus, acceptable revisions are those that constitute progress in the growth of knowledge (Popper 1972a, chapter 4, sections 19 and 20).

It is often objected that accepted observation statements, being theoryladen, may be false; so a theory that is falsified by such a statement might be true. However, observation statements may be tested also, so a previously accepted observation statement may be rejected later. For instance, a statement of the form 'this is a glass of water' implies that the liquid in the glass will behave in the law-like way that water does; and that implication may be inconsistent with other observation statements (Popper 1972a, chapter 5 and appendix $* x,(2))$. Admittedly, we can never be sure that an observation statement is true or, correlatively, that a falsified theory is false; but we can, if we are lucky, obtain theories that are better than any that we have so far and we can also adopt procedures that prohibit us from accepting a new theory, or an amendment to theory, that constitutes a regress in the growth of knowledge. We do that by prohibiting "ad hoc manoeuvres" or "conventionalist stratagems" which save a theory from falsification without solving any additional problem (Popper 1972a, chapter 4, sections 19 and 20).

It is sometimes objected that such progress in the growth of knowledge may be achieved even if all our accepted theories and observation statements are false. But that sort of objection just returns to the justificationist quagmire. We cannot know whether our theories are true or false; but, as Popper showed, we can recognise when we are making epistemic progress, that is, when we have theories that explain more, or more simply, than their predecessors and that successfully predict novel facts.

\section{Rational action}

The fact that, although we cannot know whether any of our theories is true, we can repeatedly propose new and more promising conjectures and attempt ruthlessly to falsify them and replace them with better ones, may be inspiring, even exhilarating, from a theoretical point of view. But from 
the point of view of practical action, the fact that even our best theories may be false can be frightening. Acting on a false theory can produce unwelcome, even calamitous, consequences. We may perhaps take some comfort from acting on the theory that has best survived criticism so far; but how can it be rational to do that if even the best theory available may be false and may, indeed, be falsified in the next moment, in fact in the very moment that we act on it? If rational action is to be possible, it may seem, there must be some principle of induction that vouches for the reliability of the currently best theory. That is the pragmatic problem of induction.

Popper's solution to the pragmatic problem of induction has satisfied few. It is to insist, first, that there can be no guarantee that the theory that has best survived criticism so far is reliable, and, second, that it is nevertheless rational to act on that theory because it is identified as the theory that has best survived criticism so far by means of a rational process (or the most rational process):

From a rational point of view we should not 'rely' on any theory, for no theory has been shown to be true, or can be shown to be true [...] But we should prefer as the basis for action the besttested theory [...] This will be 'rational' in the most obvious sense of the word known to me: the best-tested theory is the one which, in the light of our critical discussion, appears to be the best so far, and I do not know of anything more 'rational' than a wellconducted critical discussion (1972c, 21-22).

$[\mathrm{P}]$ ractical preference for the theory which in the light of the rational discussion appears to be nearer the truth is risky but rational (1972b, 282).

When faced with the need to act, on one theory or another, the rational choice was to act on that theory - if there was onewhich so far had stood up to criticism better than its competitors had $(1974,82)$.

[I]n so far as we accept, or reject, a scientific theory as a basis for practical action, this means choosing one theory rather than another. Where we are in the position to make such a choice, it will be rational to choose, of the two competing theories, that which has survived prolonged critical discussion, including tests $(1983,62)$. 
Some philosophers find Popper's solution unsatisfactory because it does not provide the justification of the currently-best theory that they think is needed to make action in line with that theory rational. Even philosophers who have been attracted to, and have accepted, Popper's conjecture-andrefutation response to the problem of induction have stumbled back into justificationism with regard to the pragmatic problem of induction. For example, Elie Zahar (1997, 144-45) says:

In theoretical science, the notion of truth as correspondence alone serves as a regulative idea. We can dispense with any inductive principle, and attribute different degrees of corroboration to our laws, without having to make a judgement on their future performance. Popper has not however been willing to admit that matters are different in technology, where the notion of reliability remains unavoidable (quoted and translated in Miller 2006, 114).

Similar misgivings are expressed by Watkins (1999, viii) and Worrall (1989). But such misgivings are misplaced. They amount to exclaiming that, when it comes to action, we want theories that we know we can rely on! That may be true; but we would simply be deluding ourselves if we thought that we could have such theories - because of the problem of induction.

A more serious problem with Popper's solution is that, in recommending that we act on the theory that has best survived criticism to date, Popper seems to have slipped into a form of inductivism. In that case, Popper's solution to the pragmatic problem of induction is inconsistent with his solution to the problem of induction. Given that Popper's solution to the problem of induction appears to be correct, his solution to the pragmatic problem of induction should be rejected. It cannot be rationally required to act on the currently best theory. That may seem counter-intuitive; but we can see that it is true if we again consider scientific practice.

Recall that Popper's response to the problem of induction is to commend that we invent numerous conjectures that we attempt to falsify. Even the theory that has best survived criticism so far should be subject to further attempts to refute it. However, a scientist who attempts to refute the theory that has best survived criticism so far is attempting to create a situation described by a statement which is inconsistent with the theory. That is, she is trying to do something that the theory that has best survived criticism 
so far says cannot be done. She does not, therefore, act as if the theory that has best survived criticism so far is true. Yet her action is rational, because the growth of knowledge requires that we test our theories. Further, her action may be successful; for she might refute the theory. For example, despite the most advanced optical theory (Kepler's) ruling out the possibility of a telescope, Galileo attempted to construct one and he succeeded (Feyerabend 1975, 105, footnote 21); and Edison's production of his electric light refuted the unanimous scientific opinion that such a light was impossible (Kuhn 1977, 238). If those people had insisted on acting in accord with the theory that had (so far) best survived the most searching criticism, they would have failed to achieve their successes.

Popper's proposed solution to the pragmatic problem of induction says that we are rationally required to act on the theory that has best survived criticism so far. His non-inductive epistemology says that we are rationally permitted, and even encouraged, to act against the theory that has best survived criticism so far (by trying to refute it). The two are inconsistent. The epistemology does not say that we are rationally required to act against the theory that has best survived criticism so far, since one is not rationally required to spend one's whole life attempting to refute the theory that has best survived criticism so far. According to the epistemology, one is rationally permitted to choose either to act on or to act against the theory that has best survived criticism so far. Of course, there are various ways of acting against a theory, or trying to refute it: to comment on the hackneyed example (for example, Worrall 1989, 258-60), if one wants to refute Galileo's 'law' of freefall, one may choose many ways to do it other than throwing oneself out of a tenth-story window.

Popper's mistake, then, was to maintain that one is rationally required to act in accord with the theory that has best survived criticism so far. That makes sense only on the assumption that the theory that has best survived criticism so far will continue to be successful, that it will not be refuted. It is a version of the inductivist 'principle of continence'

perform the action judged best on the basis of all available relevant reasons (Davidson 1980, 41).

Given his anti-inductivist epistemology Popper should instead have maintained that, while it is rationally permitted to act in accord with the 
theory that has best survived criticism so far, it is also rationally permitted to act against it (as, in fact, scientists often do). This is the only solution to the pragmatic problem of induction that is consistent with Popper's epistemology and the only solution that is consistent with the logical facts. Moreover, it is a solution consistent with the behaviour of scientists, who often try to refute the theories that have best survived criticism so far, and of people generally when deciding how to act (recall Edison).

Popper sometimes comes close to stating this solution:

it is perfectly reasonable to act on the assumption that [the future] will, in many respects, be like the past, and that well-tested laws will continue to hold (since we can have no better assumption to act upon); but it is also reasonable to believe that such a course of action will lead us at times into severe trouble, since some of the laws on which we now heavily rely may easily prove unreliable $(1963,56)$.

However, that he did not quite get there can be seen from the emphasis he places on the word 'act,' which shows him contrasting the pragmatic with the logical or epistemic problem of induction.

\section{Conclusion}

It seems that we naturally assume that some of our general theories about the world are justified by our observations. Yet our observations, being of particular events, give no legitimate grounds for general propositions. That is the problem of induction. Generally, the responses of philosophers have been attempts to solve the problem positively by, forlornly, defending the natural assumption. In contrast, Popper resolved the problem negatively, by pointing out that the falsity of the natural assumption does not prevent us from gaining ever-better general theories about the world, by reaching agreement on descriptions of particular events that we observe, formulating explanatory general theories about the world, and then testing those theories against the agreed descriptions of observed events.

It seems that we naturally assume that rationality requires that we act as if our best-tested theories are true. Yet the problem of induction shows 
that our best-tested theories may be false. That is the pragmatic problem of induction. Generally, the responses of philosophers have been attempts to solve the problem positively by defending the natural assumption. That would work if there were a successful positive solution to the problem of induction; but there cannot be such. Popper's attempt to combine a positive solution to the pragmatic problem of induction with his negative solution to the problem of induction was self-contradictory.

Like the problem of induction, the pragmatic problem of induction has only a negative solution. The natural assumption is that rationality requires that we act as if our best-tested theories are true. But the natural assumption is false. Rationality permits us to act in accord with our best-tested theories, since they may be true; but it also permits us to act against them, precisely because our best-tested theories may be false and may, indeed, be refuted when we act against them. As Popper often emphasised (1994, 12), the growth of our knowledge is marked by the revolutionary overthrow of theories that had previously been successful.

\section{References}

Davidson, Donald. 1980. "How is Weakness of the Will Possible?" In Donald Davidson, Essays on Actions and Events, 21-42. Oxford: Clarendon Press.

Feyerabend, Paul. 1975. Against Method. London: New Left Books.

Frederick, Danny. 2016. "Ethical Intuitionism: A Structural Critique." Journal of Value Inquiry 50 (3): 631-47. https://doi.org/10.1007/s10790-016-9547-8

Hume, David. 1888. A Treatise of Human Nature, Book I, edited by L. A. SelbyBigge. Oxford: Clarendon.

Hume, David. 1975. An Enquiry Concerning Human Understanding. In David Hume, Enquiries, edited by L. A. Selby-Bigge, third edition, 1-165. Oxford: Clarendon.

Kuhn, Thomas. 1977. "The Essential Tension." In Thomas Kuhn, The Essential Tension, 225-39. Chicago: University of Chicago Press.

Miller, David. 2006. "Induction: A Problem Solved." In David Miller, Out of Error, 111-32. Abingdon: Ashgate.

Popper, Karl. 1963. "Science: Conjectures and Refutations." In Karl Popper, Conjectures and Refutations, 33-65. London: Routledge.

Popper, Karl. 1972a. The Logic of Scientific Discovery. London: Hutchinson.

Popper, Karl. 1972b. "Addendum." In (Popper 1972a, 281-82). 
Popper, Karl. 1972c. "Conjectural Knowledge: My Solution of the Problem of Induction." In Karl Popper, Objective Knowledge 1-31. Oxford: Clarendon.

Popper, Karl. 1974. "Intellectual Autobiography." In The Philosophy of Karl Popper, Vol. 1, edited by Paul Arthur Schilpp, 3-181. La Salle, IL: Open Court.

Popper, Karl. 1983. Realism and the Aim of Science. London: Routledge.

Popper, Karl. 1994. "The Rationality of Scientific Revolutions." In Karl Popper, The Myth of the Framework, 1-32. London: Routledge.

Russell, Bertrand. 1959. My Philosophical Development. London: George Allen and Unwin.

Watkins, John. 1999. Human Freedom After Darwin. La Salle, IL: Open Court.

Worrall, John. 1989. "Why Both Popper and Watkins Fail to Solve the Problem of Induction." In Freedom and Rationality, edited by Fred D'Agostino and Ian Jarvie, 257-96. Dordrecht: Kluwer.

Zahar, Elie. 1997. Leçons d'épistémologie. Paris: CREA/École polytechnique. 